\title{
Efficiency Criteria for Thermal Insulation Structures of Glass Furnaces
}

\author{
David V. Beknazaryan*a, \\ Georgij E. Kanewets ${ }^{b}$ and Konstantin V. Strogonov \\ ${ }^{a} H I M M A S H-A P P A R A T$ limited liability company \\ Dubna, Russian Federation \\ ${ }^{b}$ Academy of Sciences of Technological Cybernetics of Ukraine \\ Kharkov, Ukraine \\ ${ }^{c}$ Research University «Moscow Power Engineering Institute» \\ Moscow, Russian Federation
}

\begin{abstract}
The optimal operation of high temperature reactors such as glass furnaces requires many factors to be considered. These are, for example, the duration of the campaign, operating costs, heat losses, trouble-free operation of units and many others, presented in the article. The aim of this study is to synthesize an efficiency criterion for optimizing the heat-insulating construction of a glass-melting furnace (HICGF), as well as obtaining the optimal values of the efficiency criterion for HICGF, which for the furnace under study are about 3.8 billion rubles. In the course of the study, the phenomenological heuristic-evolutionary optimization method by G. E. Kanevets (PHEOM. GEK), which has a number of advantages over other evolutionary methods. As the main generalizing criterion, taking into account the most significant production (volume, cost of the produced glass mass) and financial (costs for the construction and operation of the HICGF, the monetary equivalent of heat losses) indicators, the maximum gross income for the furnace campaign was adopted, which differs from prototypes in that it allows to take into account most fully the peculiarities of the work of the insulated side fence of the glass furnace. Using the software complex created on the basis of PHEOM.GEK complex systems for the side fence of a glass-melting furnace, the optimal set (sequence of location and thickness) of thermal insulation materials HICGF was determined, which allow maximizing the furnace campaign with minimal heat losses. The reliability of the data obtained is achieved by the correct use of the theory of heat and mass transfer and PHEOM.GEK. An efficiency criterion is proposed, which, by solving an optimization problem, made it possible to determine the optimal HICGF. The solution of the optimization problem in conjunction with the calculation of the duration of the furnace campaign makes it possible to form recommendations for the development of optimal HICGFs in the construction of new and cold repair of existing glass furnaces by specialized institutes and industrial companies.
\end{abstract}

Keywords: glass furnace, thermal insulation construction, optimization, efficiency criterion.

(C) Siberian Federal University. All rights reserved

This work is licensed under a Creative Commons Attribution-Non Commercial 4.0 International License (CC BY-NC 4.0).

* Corresponding author E-mail address: david_beck@mail.ru, gekan37@gmail.com, strogonovkv@yandex.ru 
Citation: Beknazaryan D. V., Kanewets G. E., Strogonov K. V. Efficiency criteria for thermal insulation structures of glass furnaces, J. Sib. Fed. Univ. Eng. \& Technol., 2021, 14(4), 459-471. DOI: 10.17516/1999-494X-0326

\title{
Критерии эффективности
}

\section{теплоизоляционных конструкций стекловаренных печей}

\author{
Д.В. Бекназарян ${ }^{\text {a }, ~ Г . Е . ~ К а н е в е ц ~}{ }^{6}$ К. В. Строгонов ${ }^{\mathrm{B}}$ \\ ${ }^{a} О О О$ «ХИММАШ-АППАРАТ» \\ Российская Федерация, Дубна \\ ${ }^{6}$ Академия наук технологической кибернетики Украинь \\ Украина, Харьков \\ ${ }^{6}$ Национальный исследовательский университет «МЭИ» \\ Российская Федерачия, Москва
}

\begin{abstract}
Аннотация. Оптимальная работа высокотемпературных реакторов, таких как стекловаренные печи, требует учета множества факторов. Это, например, длительность кампании, эксплуатационные расходы, тепловые потери, безаварийная работа агрегатов и множество других, представленных в статье. Целью настоящего исследования является синтез критерия эффективности для проведения оптимизации теплоизоляционной конструкции стекловаренной печи (ТКСП), а также получение оптимальных значений критерия эффективности для ТКСП, которые для исследуемой печи составляют 3,8 млрд руб. В процессе исследования в качестве метода оптимизации ТКСП применен феноменологический эвристико-эволюционный метод оптимизации Г.Е. Каневца (ФЭЭМО.ГЕК), который обладает рядом преимуществ по сравнению с иными эволюционными методами. В качестве основного обобщающего критерия, учитывающего наиболее значимые производственные (объем, стоимость выпускаемой стекломассы) и финансовые (затраты на сооружение и эксплуатацию ТКСП, денежный эквивалент тепловых потерь) показатели, принят максимальный валовой доход за кампанию печи, который отличается от прототипов тем, что позволяет наиболее полно учесть особенности работы именно теплоизолированного бокового ограждения стекловаренной печи. Используя созданный на основе ФЭЭМО.ГЕК сложных систем программный комплекс применительно к боковому ограждению стекловаренной печи, определен оптимальный набор (последовательность расположения и толщины) теплоизоляционных материалов ТКСП, которые дают возможность максимально продлить кампанию печи при минимальных тепловых потерях. Достоверность полученных данных достигается корректным использованием теории тепломассобмена и ФЭЭМО.ГЕК.

Предложен критерий эффективности, который посредством решения оптимизационной задачи позволил определить оптимальную ТКСП. Решение оптимизационной задачи в комплексе с расчетом длительности кампании печи помогает формировать рекомендации по освоению оптимальных ТКСП при сооружении новых и холодном ремонте существующих стекловаренных печей профильными институтами и промышленными компаниями.
\end{abstract}

Ключевые слова: стекловаренная печь, теплоизоляционная конструкция, оптимизация, критерий эффективности.

Цитирование: Бекназарян, Д. В. Критерии эффективности теплоизоляционных конструкций стекловаренных печей / Д. В. Бекназарян, Г.Е. Каневец, К. В. Строгонов // Журн. Сиб. федер. ун-та. Техника и технологии, 2021, 14(4). С. $459-471$. DOI: $10.17516 / 1999-494 X-0326$ 
Введение. Высокая эффективность основных технологических установок стекольной промышленности (стекловаренных печей) зависит от значительного количества факторов. В работах [1-3] В.Я. Дзюзером приведены данные о конструировании эффективных, в тепловом отношении, ограждений стекловаренных печей. Работы $[4,5]$ посвящены применению новых теплоизоляционных материалов в высокотемпературных агрегатах. В работах $[6,7]$ отражены данные о способе минимизации тепловых потерь через боковое ограждение стекловаренной печи, а также об оптимальном режиме работы системы принудительного воздушного охлаждения бокового ограждения стекловаренной печи.

По данным [8], методы поиска экстремума критериев эффективности сложных систем делят на три большие группы: а) прямые; б) декомпозиционные; в) методы структурной оптимизации. Наряду с перечисленными, в современной практике широко реализуются эволюционные методы, в частности биологический (метод нейронных сетей и генетические методы). В работах В.В. Курейчика [9] рассмотрено применение некоторых эволюционных и генетических методов оптимизации.

Выбор нами в настоящем исследовании феноменологического эвристико-эволюционного метода оптимизации Г.Е. Каневца (ФЭЭМО.ГЕК) связан с рядом преимуществ (некоторые из них перечислены в [10]): позволяет рассматривать элементы системы, учитывая их внутреннюю структуру, избегать необходимости преобразования информации об элементах системы из внешнего представления во внутреннее и наоборот. ФЭЭМО.ГЕК по сравнению с биологическими методами обучается при помощи заранее разработанных эвристик и не зависит от числа выполненных ранее оптимизаций и выбранных для этого примеров.

Для вновь проектируемых объектов перед конструкторами и технологами стоит сложная задача выбора наилучшего варианта конструктивного исполнения и режима работы установки из имеющейся базы зарекомендовавших себя решений с возможным внедрением собственных подходов в данных направлениях. Достижение поставленных целей осуществляется с помощью оптимизации (поиска наилучшего варианта) на этапе конструкторских работ и составления технологии реализации процесса стекловарения. Критерий, который путем обобщения всех свойств объекта (показателей эффективности - параметров, количественно определяющих меру соответствия данного свойства его целевому предназначению) позволяет количественно оценить уровень его эффективности в целом, называется критерием эффективности (или целевой функцией). Известно пять видов критериев эффективности: термодинамические, энергетические, комбинированные (удельные), экономические, натуральные [11]. Как правило, наиболее полную информацию об исследуемом объекте несут критерии, основанные на экономических показателях. Многослойная теплоизоляционная конструкция бокового ограждения печи дает возможность минимизировать тепловые потери агрегата, тем самым уменьшить затраты на варку стекломассы (из-за снижения расхода топлива). Вместе с тем применение изоляции ведет к повышению температуры огнеупорных брусьев, что способствует резкому росту скорости физико-химической коррозии в зоне контакта расплав-огнеупорный брус. Это приводит к сокращению срока службы ограждения и останову печи на холодный ремонт. Поэтому для оценки эффективности теплоизоляционной конструкции стенового ограждения необходимо синтезировать критерий эффективности, который позволит объединить параметры, влияющие на дли- 
тельности кампании печи, ее тепловую эффективность и экономические показатели работы агрегата.

Функциональная классификация критериев эффективности. Обоснование критериев эффективности является решающей стадией формулирования целей функционирования оборудования и установок. Для этого необходимо учитывать все особенности и свойства системы, ее подсистем и элементов, условия их функционирования, взаимодействия внутри системы и с внешней средой.

Известно, что любая сложная система имеет иерархическую структуру. Эффективность элементов на нижних уровнях иерархии иногда оценивается с помощью натуральных (технических, технологических) критериев. Более универсальными являются экономические критерии. Они более объективны, так как с помощью денежных эквивалентов трансформируют, сводят воедино качественные и количественные характеристики систем и их элементов, множество частных показателей эффективности.

Эффективность любого объекта выражает соотношение полученного результата и затрат для его достижения. В общем случае требуются такие крупные характеристики, как капитальные вложения, обеспечивающие создание объекта (по всем этапам «жизненного» цикла), ежегодные текущие затраты, необходимые для нормального функционирования объекта, и потребительский, народнохозяйственный эффект, выражающий результат использования объекта.

Все критерии можно разделить на две группы:

1. Критерии отдельных элементов систем и подсистем.

2. Критерии систем и подсистем.

Критерии и показатели эффективности химико- и энерготехнологических систем и их элементов подробно рассмотрены в монографиях Г.Е. Каневца [11-19]. Они систематизируются по главным классификационным признакам:

- виду (например, натуральный, энергетический, термодинамический, экономический);

• структуре (абсолютный, удельный, относительный, свернутый);

• уровню (глобальный, локальный, обобщенный);

- приложению (относительно этапов «жизненного» цикла);

- масштабу использования (народное хозяйство, отрасль, промышленное объединение);

- сроку действия (оперативный, годовой, пятилетний, долгосрочный).

Классификацию структуры критериев можно расширить следующими позициями: простой, аддитивный, мультипликативный, комплексный. Такая классификация носит общий характер и, естественно, является укрупненной.

Технико-экономические критерии эффективности энерготехнологических объектов. Технико-экономические критерии более объективны, так как они посредством денежных эквивалентов объединяют качественно различные свойства объекта, характеризуют соотношение экономического результата и затрат, вызвавших данный результат.

Для наиболее полной оценки эффективности объекта, как правило, необходимо использовать обобщенные экономические критерии эффективности, которые должны учитывать как себестоимость и качество продукции, так и производительность системы и т. д. К таким обобщенным экономическим критериям относятся: средняя прибыль, средняя рентабельность, приведенный доход, приведенные затраты и т. д.

$$
-462-
$$


Экономические критерии эффективности технических систем, как правило, являются аддитивными, то есть представляют собой сумму критериев эффективности элементов. Поэтому основная сложность и подавляющая часть трудоемкости расчета критериев техникоэкономической эффективности технических систем находится на уровне расчета критериев эффективности элементов.

Ниже приведены критерии и показатели экономической эффективности [11], которые могут быть использованы при оптимизации стекловаренной печи в целом или ее элементов:

1. Суммарные капитальные вложения в элемент (стремятся к минимуму)

$$
K=K_{\ni}+K_{\mathrm{u}}+K_{\mathrm{o}}+K_{\Phi}+K_{\text {мк }}+K_{\text {киа }} \rightarrow \text { мин, }
$$

где $K_{э}$ - стоимость элемента, его транспортировки, монтажа, капитальных ремонтов (может также учитываться приходящаяся на элемент часть стоимости зданий, сооружений, накладных расходов и т. п.), руб.; $K_{\text {и }}, K_{0}, K_{\phi}, K_{\text {мк }}, К_{\text {киа }}$-аналогичные стоимостные характеристики для изоляции, обвязки, фундаментов, металлоконструкций, КИП и автоматики, руб.

2. Используются различные приемы калькуляции цены оборудования. Среди них чаще всего применяются следующие показатели эффективности:

$$
\begin{aligned}
& Ц=C_{\text {и }}+\rho L \rightarrow \text { мин, } \\
& Ц I=C_{\text {и }}(1+\rho) \rightarrow \text { мин, } \\
& Ц=C_{\text {и }}+\rho K_{\text {оо }} \rightarrow \text { мин, }
\end{aligned}
$$

где $\mathrm{C}_{\text {и }}$ - себестоимость изготовления оборудования, руб.; $\rho$ - отраслевая норма прибавочного продукта, руб.; L - суммарные затраты живого труда (заработная плата), руб.; $\mathrm{K}_{\text {оо }}$ - объем основных и оборотных средств, руб.

3. Цена энергии

$$
L_{\mathrm{E}} \rightarrow \text { мин. }
$$

4. Себестоимость функционирования оборудования

$$
C=f\left(K, Ц_{\mathrm{E}}, Ц_{\mathrm{cp}}, a, p\right) \rightarrow \mathrm{Mин},
$$

где К - капитальные вложения в оборудование, руб.; Цср - цена рабочих сред, руб.; а, р - отчисления на амортизацию, текущий ремонт и содержание оборудования, руб.

5. Приведенные затраты (показатель сравнительной экономической эффективности)

$$
3_{\text {пр }}=C+E_{\mathrm{н}} \cdot \mathrm{K} \rightarrow \text { мин, }
$$

где $\mathrm{E}_{\text {н }}$ - нормативный коэффициент экономической эффективности ( $\left.\approx 0,15-0,3\right)$, обратный нормативному сроку окупаемости $\mathrm{T}_{\mathrm{H}}=1 / \mathrm{E}_{\mathrm{н}}$ дополнительных капитальных вложений, лет.

6. Годовой экономический эффект (показатель сравнительной экономической эффективности)

$$
Э_{\text {г }}=3_{\text {пр. }}-3_{\text {пр.н }} \rightarrow \text { макс, }
$$


где $3_{\text {пр.б. }} 3_{\text {пр.н }}-$ приведенные затраты, соответственно, базового (исходного) и нового вариантов, pyб. В случае $3_{\text {пр.б}}=$ const данный критерий превращается в $3_{\text {пр }}(7)$.

7. Коэффициент общей (абсолютной) народнохозяйственной эффективности

$$
Э_{\mathrm{a}}=\sum \ni_{\mathrm{i}} / \mathrm{K} \rightarrow \mathrm{Ma \kappa c}
$$

где $\Sigma Э_{\text {i }}$ с сумма положительных эффектов, вызываемых внедрением оборудования, руб.

8. Коэффициент хозрасчетной абсолютной эффективности

$$
\ni_{\mathrm{ax}}=(L-C) / K \rightarrow \text { макс, }
$$

где C - объум выпуска продукции в денежном выражении, руб.

9. Народнохозяйственный доход

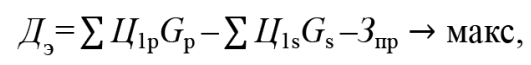

где Ц $_{\mathrm{p}}$ - цена продукции р-того вида продукции при использовании оборудования, руб.; $\mathrm{G}_{\mathrm{p}}$ объем выпуска р-того вида продукции, т; Ц ${ }_{I s}, G_{s}$ - аналогичные показатели для сырья.

10. Безразмерный коэффициент экономической эффективности

$$
\eta=3_{\text {пр }} / 3_{\text {пр. } э} \rightarrow \text { мин, }
$$

где $3_{\text {пр. э }}$ - приведенные затраты эталонного оборудования, относительно которого оценивается эффективность исследуемого оборудования.

11. Параметр нейтральной эффективности (характеризует эффективность процесса в элементе при единичных затратах)

$$
Q_{3}=Q / 3_{\text {пр }} \rightarrow \text { макс, }
$$

где $Q$ - количество производимой элементом продукции (например, тепла, мощности, веществ) в натуральном выражении.

Для теплоизоляционных конструкций данный параметр имеет аналогичную математическую формулировку, но стремится к минимуму

$$
Q_{3}=Q / 3_{\text {пр }} \rightarrow \text { макс, }
$$

где $Q$ - количество теплоты, теряемое с 1 м погонного теплоизоляционной конструкции, Вт.

12. Интегральные приведенные затраты (затраты за весь «жизненный» цикл оборудования как показатель сравнительной эффективности)

$$
3_{\text {пр }}^{\text {инт }}=\sum_{\tau=1}^{\tau=\tau_{\text {жщ }}}\left(C_{\tau}+E_{\mathbf{H}_{1}} K_{\tau-} a_{\tau}\right) b_{\tau} \rightarrow \text { мин, }
$$

где $\tau_{\text {жц }}$ общая продолжительность всех этапов «жизненного» цикла оборудования; $\mathrm{a}_{\tau}-$ aмортизационные расходы $\tau$-го года; $b_{\tau}-$ коэффициент приведения $\tau$-го года к начальному.

13. Интегральный экономический эффект (показатель сравнительной эффективности)

$$
\ni_{\text {пр }}^{\text {инт }}=\sum_{\tau=1}^{\tau \tau \tau_{\text {жи }}} \sum_{\mathrm{p}} I U_{1 \mathrm{p \tau}} G_{\mathrm{p \tau}}-3_{\text {пр }}^{\text {инт }} \rightarrow \text { макс, }
$$

где все составляющие данного критерия приведены выше. В $3^{\text {инт }}$ пр здесь входит также стоимость все видов сырья $\Sigma Ц_{1 \mathrm{~s}} G_{\mathrm{s}}$. 
Как видно из приведенных формул, среди экономических критериев по структуре встречаются как удельные, так и комбинированные.

Ввиду того, что суточная производительность печи на протяжении кампании остается неизменной, то вычитаемое в уравнении (3) является постоянной величиной и ее можно не рассматривать в критерии эффективности.

Окончательно в качестве критерия эффективности можно принять годовые затраты на эксплуатацию теплоизоляционной конструкции, руб.:

$$
3_{\text {ЭТКСП }}^{\text {год }}=\left(Э_{\text {год }}+\frac{K}{\tau_{э}}+\frac{Q_{\text {потерь }}}{Q_{\mathrm{H}}^{\mathrm{p}}} \cdot Ц_{\text {пр.г }}\right),
$$

где - время эксплуатации стекловаренной печи до остановки агрегата на холодный ремонт, лет.

Технико-экономические критерии эффективности, применимые к стекловаренной печи. Размерность оптимизационной задачи зависит от факторов, влияющих на выбранный критерий эффективности. Расчет скорости коррозии, а следовательно, и продолжительности срока службы огнеупорного бруса варочного бассейна зависит от уровня температуры на границе расплав стекломассы-огнеупорный материал. Данная температура, в свою очередь, зависит от геометрических, начальных и граничных условий, типов огнеупорных и теплоизоляционных материалов, используемых в боковых ограждениях, интенсивности теплообмена при естественной и вынужденной конвекции на наружных поверхностях стеновых брусьев и теплоизоляционных панелей.

При наложении тепловой изоляции на наружную поверхность стеновых брусьев рабочего пространства и варочного бассейна происходит существенное повышение температуры внутренней поверхности огнеупорного бруса. В варочной зоне это вызывает интенсификацию коррозионных процессов на границе расплав стекломассы - стеновой брус. При этом в случае применения системы принудительного воздушного охлаждения для наружной поверхности бруса на линии зеркала стекломассы зона максимальной интенсивности коррозионных процессов смещается с границы раздела трех фаз (огнеупорный материал - расплав стекломассы пламенное пространство) в глубину бассейна, покрытую тепловой изоляцией.

Таим образом, целесообразно рассмотреть задачу минимизации тепловых потерь через боковое ограждение печи при максимальном периоде работы огнеупорных брусьев в случае использования принудительного воздушного охлаждения наружной поверхности варочного бассейна на линии зеркала стекломассы. Снижение тепловых потерь через боковое ограждение достигается применением различных вариантов компоновки теплоизоляционных панелей зоны варочного бассейна путем изменения толщины и марки теплоизоляционных материалов, составляющих теплоизоляционную панель.

Экономическое обоснование целесообразности использования какого-либо варианта изоляционных панелей требует ввода в обиход критерия эффективности, позволяющего сопоставить затраты на тепловую изоляцию и затраты за счет тепловых потерь через теплоизоляционную конструкцию, имеющих место при эксплуатации ограждения с данным набором изоляционных материалов.

В качестве критерия эффективности предложено использовать величину максимального валового дохода за кампанию печи, руб.

$$
-465-
$$


Значение ежегодного максимального валового дохода:

$$
\not_{\text {вал.max }}^{\text {год }}=\mathrm{G}_{\text {год }} L_{\text {ст }}-\left(Э_{\text {год }}+\frac{K}{\tau_{\ni}}+\frac{Q_{\text {потерь }}}{Q_{\mathrm{r}}^{\mathrm{p}}} \cdot L_{\text {пр.г }}\right),
$$

где - время эксплуатации стекловаренной печи отпуска до остановки агрегата на холодный ремонт (кампания печи), лет/кампания;

- годовое количество выпускаемой продукции, т/год;

- средняя цена тонны стекломассы при отпуске с предприятия, руб./т;

- стоимость природного газа, руб./м³;

- годовые затраты на эксплуатацию бокового ограждения (в том числе на систему принудительного охлаждения), руб./год;

- капитальные вложения в ограждение, руб./кампания;

- среднеинтегральное значение тепловых потерь изоляционной конструкции в год, кВт/год.

Помножив левую и правую части на время эксплуатации стекловаренной печи, получаем:

$$
Д_{\text {вал. } \max }^{\text {год }} \tau_{\ni}=G_{\text {год }} U_{\text {ст }} \tau_{\ni}-\left(Э_{\text {год }} \tau_{\ni}+K+\frac{Q_{\text {потерь }}}{Q_{\mathrm{H}}^{\mathrm{p}}} \cdot Ц_{\text {пр.г }} \tau_{\ni}\right) \text {. }
$$

Итоговый вид критерия эффективности (максимальный валовой доход за кампанию печи) после преобразований:

$$
Д_{\text {вал.max }}=G_{\text {год }} U_{\text {ст }} \tau_{\ni}-\left(Э_{\text {год }} \tau_{\ni}+K+\frac{Q_{\text {потерь }}}{Q_{\mathrm{H}}^{\mathrm{p}}} \cdot Ц_{\text {пр. . }} \tau_{\ni}\right) .
$$

Оптимальным вариантом ТКСП является такая комбинация теплоизоляционных материалов соответствующей толщины, которая обеспечит максимальное значение критерия эффективности.

Параметры, от которых зависит критерий эффективности, выбраны исходя из реальных технологических условий, оказывающих наибольшее влияние на процесс варки стекломассы. Такие параметры приведены ниже в характерных для современных стекловаренных печей диапазонах. Среди них: перепад температуры по глубине бассейна; температура рабочего пространства; температура зеркала стекломассы; коэффициенты теплообмена, обеспечиваемые системой принудительного воздушного охлаждения; толщина теплоизоляционных материалов зоны варочного бассейна; стоимость теплоизоляционных материалов; стоимость природного газа.

В качестве независимых переменных взяты следующие параметры [19, 20]:

І режимные

1) изменение перепада температуры по глубине варочного бассейна, ${ }^{\circ} \mathrm{C}$ :

$1 \Delta \mathrm{t}=150$

$2 \Delta \mathrm{t}=130$

$3 \Delta \mathrm{t}=110$

$4 \Delta \mathrm{t}=90$

2) изменение температуры варки на поверхности стекломассы и соответствующая ей температура пламенного пространства, ${ }^{\circ} \mathrm{C}$ :

$$
\begin{array}{ll}
1 \mathrm{t}_{\text {зер }}=1475 ; & \mathrm{t}_{\text {пл. пр }}=1525 ; \\
2 \mathrm{t}_{\text {зер }}=1500 ; & \mathrm{t}_{\text {пл. пр }}=1550 ;
\end{array}
$$


$3 \mathrm{t}_{\text {зер }}=1525 ; \mathrm{t}_{\text {пл. пр }}=1575$

$4 \mathrm{t}_{\text {зер }}=1550 ; \mathrm{t}_{\text {пл. пр }}=1600$;

3) интенсивность принудительного воздушного охлаждения, Вт/(м²К) [19, 21]:

$1 \alpha_{\text {возд. прин. }}=200$;

$2 \alpha_{\text {возд. прин. }}=240$;

$3 \alpha_{\text {возд. прин. }}=300$;

$4 \alpha_{\text {возд. прин. }}=360$;

II конструктивные

1) изменение толщины теплоизоляционной панели КПД- 400 в зоне варки, мм:

$1 \delta_{\text {КПд- } 400}=230$;

$2 \delta_{\text {Кпд- } 400}=114$

$3 \delta_{\text {Кпд- } 400}=65$;

2) изменение толщины теплоизоляционной панели КПД-500 в зоне варки, мм:

$1 \delta_{\text {кпд-500 }}=230$;

$2 \delta_{\text {кпд-500 }}=114$;

$3 \delta_{\text {Кпд- } 500}=65$;

3) изменение толщины теплоизоляционной панели ШЛ-0,4 в зоне варки, мм:

$1 \delta_{\text {Шл- } 0,4}=230$;

$2 \delta_{\text {ШЛ- } 0,4}=114 ;$

$3 \delta_{\text {шл- } 0,4}=65$;

4) изменение толщины теплоизоляционной панели ШЛ-0,9 в зоне варки, мм:

$1 \delta_{\text {Шл- } 0,9}=230$;

$2 \delta_{\text {ШЛ- } 0,9}=114 ;$

$3 \delta_{\text {шл- } 0,9}=65$;

5) изменение толщины теплоизоляционной панели ШТЛ-0,6 в зоне варки, мм:

$1 \delta_{\text {штл-0,6 }}=230$;

$2 \delta_{\text {штл- } 0,6}=114$;

$3 \delta_{\text {штл- } 0,6}=65$;

6) изменение толщины материала КЛ-1.1:

$1 \delta_{\text {кл-1.1 }}=230$;

$2 \delta_{\text {кл-1.1 }}=114$;

$3 \delta_{\text {кл-1.1 }}=65$;

III экономические

1) цена природного газа за $1000 \mathrm{~m}^{3}$, руб.

$1 Ц_{\text {прир.г. }}=4946,56$.

Итого 46656 вариантов расчета.

С использованием синтезированного критерия эффективности были выполнены расчеты по определению оптимальной комбинации материалов ТКСП (которая обеспечит максимальную длительность кампании при минимальных тепловых потерях с наружных поверхностей стекловаренной печи).

По результатам проведенных расчетов для стекловаренной печи, габариты которой составляют 13,7×8,6×2,55 м (производительность по стеклу составляет 280 т/сут), с использовани- 
ем синтезированного критерия эффективности была составлена табл. 1 , в которой приведены значения параметров, которые входят него. В табл. 2 приведены некоторые параметры, получаемые при расчете критерия эффективности.

Остаточная толщина огнеупорного бруса, контактирующего со стекломассой, для безопасной эксплуатации $\delta_{\text {ост }}=40$ мм.

Стоимость листового стекла (толщина 4 мм) цст $=32045,8$, руб./т.

Низшая теплота сгорания природного газа $=35,7$ МДж/ $\mathrm{M}^{3}$.

Таблица 1. Параметры, входящие в критерий эффективности

Table 1. Parameters included in the performance criterion

\begin{tabular}{|c|l|c|c|c|c|}
\hline \multirow{2}{*}{$\begin{array}{c}\text { № } \\
\text { п/п }\end{array}$} & \multicolumn{1}{|c|}{ Наименование параметра } & \multicolumn{4}{|c|}{ Значение } \\
\cline { 3 - 6 } & $\begin{array}{c}\text { Вариант 1 } \\
\text { базовый }\end{array}$ & Вариант 2 & $\begin{array}{c}\text { Вариант 3 } \\
\text { оптимальный }\end{array}$ & Вариант 4 \\
\hline 1. & Длительность кампании $\tau_{3}$, сут & 427 & 430 & 438 & 432 \\
\hline 2. & $\begin{array}{l}\text { Общий выпуск стекломассы } \\
\text { за кампанию печи G, т }\end{array}$ & 119560 & 120400 & 122640 & 120960 \\
\hline 3. & $\begin{array}{l}\text { Эксплуатационные расходы Э, } \\
\text { руб. }\end{array}$ & 2941749 & 2962417 & 3017532 & 2976195 \\
\hline 4. & $\begin{array}{l}\text { Капитальные затраты } \\
\text { на сооружение ТКСП, тыс. руб. }\end{array}$ & 4045,18 & 3925,96 & 3986,39 & 4073,99 \\
\hline 5. & $\begin{array}{l}\text { Величина тепловых потерь } \\
\text { с поверхности бокового } \\
\text { ограждения за период кампании } \\
\text { Qпотьр, ГДж }\end{array}$ & 26702,7 & 37164,1 & 23809,4 & 35171,5 \\
\hline 6. & $\begin{array}{l}\text { Максимальный валовой доход } \\
\text { за период кампании печи } \\
\text { Двал.тах, млн руб. }\end{array}$ & 3820,23 & 3846,27 & 3919,22 & 3846,33 \\
\hline
\end{tabular}

Таблица 2. Расчетные величины для различных вариантов ТКСП

Table 2. Calculated values for different versions of the HIGF

\begin{tabular}{|c|c|c|c|c|c|}
\hline \multirow{2}{*}{$\begin{array}{l}\text { № } \\
\text { п/п }\end{array}$} & \multirow[b]{2}{*}{ Наименование параметра } & \multicolumn{4}{|c|}{ Значение } \\
\hline & & $\begin{array}{l}\text { Вариант } 1 \\
\text { базовый }\end{array}$ & Вариант 2 & $\begin{array}{c}\text { Вариант } 3 \\
\text { оптимальный }\end{array}$ & Вариант 4 \\
\hline 1. & Длительность кампании $\tau_{9}$, сут & 427 & 430 & 438 & 432 \\
\hline 2. & $\begin{array}{l}\text { Величина тепловых потерь } \\
\text { с поверхности бокового } \\
\text { ограждения за период кампании } \\
\text { в пересчете на природный газ, } \\
\text { тыс. м³ }\end{array}$ & 747,97 & 1041,01 & 666,92 & 985,194 \\
\hline 3. & $\begin{array}{l}\text { Денежный эквивалент тепловых } \\
\text { потерь, руб. }\end{array}$ & 3699879 & 4873325 & 3299003 & 4873321 \\
\hline 4. & Часовой расход топлива, нм³/ч & 1313,47 & 1353,85 & 1299,66 & 1345,38 \\
\hline 5. & $\begin{array}{l}\text { Удельный расход топлива } \\
\text { на тонну сваренной } \\
\text { стекломассы, нм³/т }\end{array}$ & 112,58 & 116,04 & 111,4 & 115,32 \\
\hline
\end{tabular}




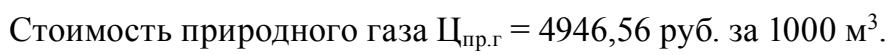

Выводы. Рассмотрена классификация критериев эффективности, а также синтезирован критерий эффективности для оптимизации ТКСП, который позволяет получить комбинацию теплоизоляционных материалов для обеспечения наибольшей длительности кампании стекловаренной печи при наименьших затратах на эксплуатацию и сооружение ТКСП. Таким критерием является валовой доход за кампанию печи с учетом затрат на сооружение ТКСП и его эксплуатацию (в том числе принудительное воздушное охлаждение). Значение максимального валового дохода за кампанию печи для оптимального варианта (№ 3) составило 3 912,22 млн руб. при длительности кампании 438 сут, общем выпуске стекломассы 122640 т и удельном расходе топлива в количестве 111,399 нм³ на 1 т сваренной стекломассы. Для ряда режимных параметров, в том числе оптимального, приведены результаты расчета ряда величин, которые позволяют оценить эффективность работы стекловаренной печи в целом.

\section{Список литературы / References}

[1] Дзюзер В.Я. Энергоэффективные печные ограждения высокопроизводительной стекловаренной печи. Огнеупоры и техническая керамика, 2009, 7-8, 48-54 [Dzyuzer V. Ya. Energyefficient oven enclosures of a high-performance glass-making furnace. Refractories and technical ceramics, 2009, 7-8, 48-54 (in Russian)]

[2] Дзюзер В.Я. Эффективное применение электроплавленных бадделеитокорундовых огнупоров в высокотемпературных стекловаренных печах. Часть 1. Огнеупоры и техническая керамика, 2004, 6, 45-49. [Dzyuzer V. Ya. Effective use of electrofused baddeleyite-corundum refractory materials in high-temperature glass-melting furnaces. Part 1. Refractories and technical ceramics, 2004, 6, 45-49 (in Russian)]

[3] Дзюзер В.Я. Эффективное применение электроплавленных бадделеитокорундовых огнупоров в высокотемпературных стекловаренных печах. Часть 1. Огнеупоры и техническая керамика, 2004, 7, 36-39. [Dzyuzer V. Ya. Effective use of electrofused baddeleyite-corundum refractory materials in high-temperature glass-melting furnaces. Part 1. Refractories and technical ceramics, 2004, 7, 36-39 (in Russian)]

[4] Апкарьян А.С., Христюков В.Г., Смирнов Г.В. Тепловая изоляция высокотемпературных агрегатов керамического производств. Стекло и керамика, 2010, 2, 18-21 [Apkarian A. S., Hristoskov V. G., Smirnov G. V. Thermal insulation of high-temperature ceramic production units. Glass and ceramics, 2010, 2, 18-21 (in Russian)]

[5] Владимиров В.С., Лукин Е.С., Попова Н.А., Илюхин М. А., Мойзис С.Е., Мойзис Е. С., Артамонов М.А. Новые виды легких огнеупорных и теплоизоляционных материалов. Стекло и керамика, 2011, 4, 14-21. [Vladimirov V. S., Lukin E. S., Popov N. A., Lyukhin M. A., Mousis S.E., Moises E.S., Artamonov M. A. New types of light refractory and thermal insulation materials. Glass and ceramics, 2011, 4, 14-21 (in Russian)]

[6] Дзюзер В.Я., Никифоров Е.А. Минимизация тепловых потерь через кладку варочного бассейна стекловаренных печей. Огнеупоры и техническая керамика. 2012, 3, 27-32. [Dzyuzer V. Ya., Nikiforov E. A. Minimization of heat losses through the masonry of the melting basin of glass-making furnaces. Refractories and technical ceramics, 2012, 3, 27-32 (in Russian)]

$$
-469-
$$


[7] Семенов Б.А., Озеров Н. А. Методика и результаты оптимизации параметров системы обдува ограждений варочного бассейна стекловаренных печей. Вестник СГТУ, 2011, 4 (59), Вып. 1, 210-217 [Semenov B. A., Ozerov N. A. Methods and results of optimization of the parameters of the system for blowing the fencing of the melting basin of glass-making furnaces. Vestnik SSTU, 2011, 4 (59), Issue 1, 210-217 (in Russian)]

[8] Бобров Д.А., Кафаров В.В., Перов В.Л. Оптимизация химико-технологических систем. М.: МХТИ, 1979. 49 с. [Bobrov D. A., Kafarov V.V., Perov V.L. Optimization of chemical engineering systems. Moscow, MHTI, 1979. 49 p. (in Russian)]

[9] Зайцев А. А., Курейчик В. В., Полупанов А. А. Обзор эволюционных методов оптимизации на основе роевого интеллекта. Известия ЮФУ. Технические науки, 2010, 12 (112), 7-12 [Zaitsev A. A., Kureichik V.V., Polupanov A. A. Review of evolutionary optimization methods based on swarm intelligence Izvestia SFU. Technical science, 2010, 12 (112), 7-12 (in Russian)]

[10] Каневец Г.Е., Берлин М. А. Феноменологический эвристико-эволюционный подход при комплексной оптимизации процесса подготовки нефти на промыслах. Нефтегаз, 2010, 1, 40-50 [Kanevets G. E., Berlin M. A. Phenomenological heuristic-evolutionary approach for complex optimization of the oil preparation process in the fields. Neftegas, 2010, 1, 40-50 (in Russian)]

[11] Каневец Г.Е. Обобщенные методы расчета теплообменников. Киев: Наукова думка, 1979, 352, 263-279 [Kanevets G.E. Generalized methods for calculating heat exchangers. Kiev: Naukova Dumka, 1979, 352, 263-279 (in Russian)]

[12] Каневец Г.Е., Сагань И. И. Оптимизащия теплообменного оборудования пищевых производств. Ред. Г.Е. Каневец, И.И. Сагань. Киев: Техніка, 1981, 192 с., 86-102. [Kanevets G.Е., Sagan I.I. Optimization of heat exchange equipment for food production. Ed. Kanevets G.E., Sagan I. I. Kiev, Tekhnika, 1981, 192 p, 86-102 (in Russian)]

[13] Kanewez G. Berechnung von Warmeübertragersystemen und deren Elementen. Berlin, Akademie Verlag, 1982, 328, 292-311.

[14] Каневец Г.Е. Теплообменники и теплообменные системы. Киев: Наукова думка, 1982, 272, 163-189 [Kanevets G.E. Heat exchangers and heat exchange systems. Kiev, Naukova Dumka, 1982, 272, 163-189 (in Russian)]

[15] Каневец Г.Е., З Зайцев И.Д., Головач И.И. Введение в автоматизированное проектирование теплообменного оборудования. Киев: Наукова думка, 1985, 232, 52-58 [Kanevets G.E., Zaitsev I.D., Golovach I.I. Introduction to computer-aided design of heat exchange equipment. Kiev: Naukova Dumka, 1985, 232, 52-58 (in Russian)]

[16] Каневец Г.Е. Проблемы исследования сложных систем и их элементов. Состояние и перспективы системных исследований химико-и энерготехнологических объектов. Киев: Наукова думка, 1986 [Kanevets G. E. Problems of research of complex systems and their elements. The state and prospects of system research of chemical and energy technology objects. Kiev, Naukova Dumka, 1986 (in Russian)]

[17] Каневец Г.Е. Пути повышения эффективности технических систем и их элементов на основе вычислительного эксперимента. Киев: Знание, 1988, 14 [Kanevets G. E. Ways to improve the efficiency of technical systems and their elements on the basis of a computational experiment. Kiev, Znanie, 1988, 14 (in Russian)] 
[18] Каневец Г.Е., Клименко, А.П., Рябченко, Н. П. Проектирование и оптимизация теплообменных аппаратов на ЭЦВМ. Часть 3. Оптимизация кожухотрубчатых теплообменников. Киев: Ин-т кибернетики АН УССР, 1970, 233 [Kanevets G. E., Klimenko A.P., Ryabchenko N.P. Design and optimization of heat exchangers on the digital computer. Part 3. Optimization of shell and tube heat exchangers. Kiev, Institute of Cybernetics, Academy of Sciences of Ukrainian Soviet Socialist Republic, 1970, 233 (in Russian)]

[19] Будов В. М. Продление межремонтного периода работы стекловаренных печей-резерв увеличения выпуска листового стекла. Стекло и керамика, 1975, 4, 4-7 [Budov V.M. Extension of the inter-repair period of glass furnaces-reserve increase in the production of sheet glass. Glass and ceramics, 1975, 4, 4-7 (in Russian)]

[20] Дзюзер В.Я. Огнеупоры для варочной части стекловаренных печей. Огнеупоры и техническая керамика, 2008, 5, 24-32 [Dzyuzer V. Ya. Firebricks for the cooking part of a glass furnace. Refractories and technical ceramics, 2008, 5, 24-32 (in Russian)]

[21] Дзюзер В.Я. Охлаждение окружки варочного бассейна стекловаренной печи Огнеупоры и техническая керамика, 2009, 8, 13-16 [Dzyuzer V. Ya. Cooling of fluxline of glass furnace pool. Refractories and technical ceramics, 2009, 8, 13-16 (in Russian)] 